\title{
Relation of the functional and structural fundus changes after submacular surgery for neovascular age-related macular degeneration
}

\author{
Henry L Hudson, Donald A Frambach, Pedro F Lopez
}

\begin{abstract}
Aims-This study was carried out to investigate the precise pattern of visual loss associated with subfoveal choroidal neovascular membranes and the mechanism by which vision is stabilised or improved after submacular surgery. Methods-Preoperative and postoperative quantitative microperimetry using the scanning laser ophthalmoscope was performed on six eyes of five patients with age-related macular degeneration who underwent subfoveal choroidal neovascular membrane excision. The relation of the microperimetry findings to the preoperative and postoperative fluorescein angiographic features was also assessed. Results-Four of the six eyes had visual improvement by the 6 month postoperative visit; the other two had stabilisation of vision at the preoperative level. Despite these beneficial visual effects, none of the patients fixated within the bed of the excised choroidal neovascular membrane. Subfoveal choroidal membrane excision was associated with a $36 \%$ average increase in the absolute scotoma at the 1 month postoperative visit, compared with the preoperative size. The postoperative scotoma appeared to remain stable or decreased slightly in size between the 6 month and 1 year postoperative visits. Recovery of vision was associated with the development of a more stable preferred eccentric fixation locus, of which the distance from the centre of the foveal avascular zone was related to final postoperative vision. Most of the eccentric fixation loci were inferotemporal to the bed of the excised choroidal neovascular membrane. The surgical retinotomy site was associated with persistent postoperative relative scotoma in five of the six cases, but resolved in one patient after 1 year.
\end{abstract}

Conclusion-These findings indicate that quantitative scanning laser ophthalmoscope microperimetry may aid in the surgical planning of subfoveal choroidal neovascular membrane excision.

(Br F Ophthalmol 1995; 79: 417-423)

Age-related macular degeneration is the leading cause of irreversible loss of vision in persons over age 50 in the United States and other Western countries. ${ }^{1-4}$ Subfoveal choroidal neovascularisation and its sequelae are responsible for up to $80 \%$ of the severe visual loss in this condition. ${ }^{2}$ Recently, surgical excision of subfoveal choroidal neovascular membranes in eyes with age-related macular degeneration has been shown to stabilise, and in some cases even improve vision. ${ }^{5-7}$ The precise pattern of visual loss associated with subfoveal choroidal neovascular membranes, as well as the mechanism by which vision is stabilised or improved after submacular surgery, is not understood, however. To investigate this, we performed preoperative and postoperative microperimetry using the scanning laser ophthalmoscope on six eyes of five patients with age-related macular degeneration who underwent subfoveal choroidal neovascular membrane excision, and examined the relation of these findings to the preoperative and postoperative photographic and fluorescein angiographic features.

\section{Materials and methods}

Six eyes of five consecutive patients with agerelated macular degeneration who underwent subfoveal choroidal neovascular membrane excision were studied in a prospective manner. The indications and surgical techniques have been described previously ${ }^{6}$ The surgery was performed by the same person (PFL). The retinotomies for extraction of the subfoveal choroidal neovascular membranes were performed in exudatively detached retina 300 to $500 \mu \mathrm{m}$ from the temporal margin of the lesions (500 to $2500 \mu \mathrm{m}$ from the centre of the foveal avascular zone as seen on fluorescein angiography). The location of the retinotomy site was recorded intraoperatively in each patient in relation to the posterior pole retinal vascular landmarks, since the retinotomy site was not identifiable clinically or angiographically following retinal reattachment.

Best corrected visual acuities on the Early Treatment of Diabetic Retinopathy Study chart $^{8}$ and Guyton-Minskowski potential acuity meter readings were obtained in each patient at the preoperative visit and at each postoperative visit. All patients had a preoperative vision $\leqslant 20 / 200(6 / 60)$. Slit-lamp and fundus biomicroscopic examination, stereo colour fundus photography, and Macular Photocoagulation Study protocol fluorescein angiography ${ }^{9}$ were performed on each patient preoperatively, as well as at each postoperative visit. The choroidal neovascular membranes were classified according to the guidelines of the Macular Photocoagulation Study. ${ }^{9}$

Microperimetry was performed on all 
patients using the Rodenstock scanning laser ophthalmoscope (Danbury, CT, USA) and software from the Schepens Eye Research Institute (Boston, MA) driving an 8-bit frame grabber (FG-100, Imaging Technologies, Woburn, MA, USA). All microperimetry studies were performed by two of the authors (HLH, PFL). The helium-neon laser was used for both background illumination and target presentation. The target was always darker than the background. The background illumination (laser power) was always set at 4.6 microwatts (as measured at the cornea). ${ }^{10}$ The stimulus (target to background) contrast settings used were $72 \%$ and $92 \%$ (92\% contrast is the maximum contrast that our scanning laser ophthalmoscope was capable of generating). In this study, the $92 \%$ stimulus contrast level was used for the detection mapping of dense (absolute) scotomas. The $72 \%$ contrast level was used to define relative scotomata. The smallest scanning laser ophthalmoscope field $\left(40^{\circ}\right.$ or $60^{\circ}$ in diameter) that encompassed the entire lesion was used. The size of the test target on the retina was $10 \times 10$ pixels. Assuming an emmetropic eye, the approximate size of the test target was $160 \mu \mathrm{m}$ for the $40^{\circ}$ field and $240 \mu \mathrm{m}$ for the $60^{\circ}$ field. A $40^{\circ}$ field size was used in the first four patients (cases 1 to 4 ) and a $60^{\circ}$ field size was used in both eyes of case 5 . Kinetic microperimetry was performed using techniques similar to those employed with a Goldmann kinetic perimeter. Using the scanning laser ophthalmoscope kinetic microperimetry technique, the examiner was able to view the macular pathology while performing the microperimetry. No fixation target was used because of the poor constancy of fixation in these patients. For each patient, the kinetic microperimetry test was performed by moving the cross target from within the scotomatous region towards the non-scotomatous periphery, as well as from non-scotomatous periphery

Table 1 Clinical characteristics of the submacular surgery patients

\begin{tabular}{|c|c|c|c|}
\hline $\begin{array}{l}\text { Patient no, } \\
\text { age (years), } \\
\text { sex, eye }\end{array}$ & $\begin{array}{l}\text { ETDRS } \\
\text { visual } \\
\text { acuity }\end{array}$ & PAM† & Choroidal neovascular membrane characteristics \\
\hline $\begin{array}{l}\text { 1, 74, F, RE } \\
\text { Preop } \\
3 \text { Months } \\
6 \text { Months } \\
12 \text { Months } \\
\text { 2, 84, F, RE }\end{array}$ & $\begin{array}{l}20 / 200 \\
20 / 400 \\
20 / 200 \\
20 / 160\end{array}$ & $\begin{array}{l}20 / 70 \\
20 / 400 \\
20 / 200 \\
20 / 200\end{array}$ & Fibrovascular PED \\
\hline $\begin{array}{l}\text { Preop } \\
1 \text { Month } \\
6 \text { Months } \\
14 \text { Months } \\
\text { 3, } 70, \mathrm{M}, \mathrm{LE}\end{array}$ & $\begin{array}{l}20 / 200 \\
20 / 400 \\
20 / 315 \\
20 / 200\end{array}$ & $\begin{array}{l}20 / 200 \\
20 / 300 \\
20 / 200 \\
20 / 200\end{array}$ & $\begin{array}{l}\text { Well demarcated CNV/scar with prior laser } \\
\text { treatment }\end{array}$ \\
\hline $\begin{array}{l}\text { Preop } \\
6 \mathrm{Months} \\
\text { 4, } 75 \mathrm{M}, \mathrm{RE}\end{array}$ & $\begin{array}{r}<20 / 800 \\
20 / 400\end{array}$ & $\begin{array}{l}<20 / 400 \\
<20 / 400\end{array}$ & Well demarcated $\mathrm{CNV} / \mathrm{scar}$ \\
\hline $\begin{array}{l}\text { Preop } \\
1 \text { Month } \\
6 \text { Months } \\
12 \text { Months } \\
5,71, \text { F, RE }\end{array}$ & $\begin{array}{r}<20 / 800 \\
<20 / 800 \\
20 / 400 \\
20 / 300\end{array}$ & $\begin{array}{r}<20 / 400 \\
<20 / 400 \\
20 / 400 \\
20 / 300\end{array}$ & Well demarcated $\mathrm{CNV} / \mathrm{scar}$ \\
\hline $\begin{array}{l}\text { Preop } \\
4 \text { Months } \\
6 \text { Months } \\
12 \text { Months } \\
\text { LE }\end{array}$ & $\begin{array}{r}<20 / 800 \\
20 / 400 \\
20 / 400 \\
20 / 400\end{array}$ & $\begin{array}{l}20 / 100 \\
20 / 300 \\
20 / 300 \\
20 / 200\end{array}$ & $\begin{array}{l}\text { Well demarcated CNV/scar with small area } \\
\text { of associated subretinal haemorrhage }\end{array}$ \\
\hline $\begin{array}{l}\text { Preop } \\
1 \text { Month } \\
6 \text { Months }\end{array}$ & $\begin{array}{r}<20 / 800 \\
20 / 400 \\
20 / 400\end{array}$ & $\begin{array}{r}<20 / 400 \\
20 / 400 \\
20 / 300\end{array}$ & Well demarcated CNV/scar \\
\hline
\end{tabular}

^Measured on the Early Treatment of Diabetic Retinopathy Study chart.

†Guyton-Minkowski potential acuity meter reading.

$\mathrm{PED}=$ pigment epithelial detachment; $\mathrm{CNV}=$ choroidal neovascular membrane. towards the scotomatous region. The smallest isoptre determined for each test stimulus was mapped on an acetate overlay. Each acetate image was then digitised using a DESKSCAN system (Apple Computer, Cupertino, CA, USA). Area measurements of each isoptre were determined using an image analysis program (Dapple Systems, Sunnyvale, CA, USA). For these calculations, the long standing clinical convention of considering the diameter of the average optic disc to be $1500 \mu \mathrm{m}$ was used to standardise our findings with those of current prospective epidemiological studies of agerelated macular degeneration, ${ }^{11}$ even though 1800 to $2000 \mu \mathrm{m}$ may be a better estimate of the optic disc diameter. ${ }^{12}$ The reproducibility of the quantitated scotoma areas was determined by three independent reproductions of each acetate image, and three separate analyses of each isoptre of eye for each image. The reproducibility of the quantitated scotoma areas using this method was found to be within $6.5 \%$ (range $2 \%$ to $10 \cdot 3 \%$ ). The microperimetry was analysed by the same person (HLH), who was masked as to the fluorescein angiographic appearance of the preoperative or postoperative lesions. Fixation behaviour, when possible, was determined by placing the stimulus cross in the physiological blind spot (optic disc) and asking the patient to search for, then fixate on, the cross. The distance from the fixation locus to the centre of the foveal avascular zone was then determined in millimetres. The quality of fixation behaviour was graded in the manner described by Acosta et al ${ }^{13}$ : grade 1, undefined, with no preferred retinal area of fixation; grade 2, preferred, but transient locus of fixation detected; and grade 3 , stable fixation with a well defined retinal locus. The follow up period was 1 year for four eyes and 6 months for two eyes.

Optimal preoperative and postoperative fluorescein angiographic frames were enlarged and photographed. The margins of each choroidal neovascular membrane were outlined on the optimal photograph from the preoperative fluorescein angiogram using the guidelines suggested by the Macular Photocoagulation Study group. ${ }^{9}$ Each scored preoperative photograph was then digitised and the lesion area was quantitated as described above. The presence of postoperative choriocapillary atrophy was defined during the retinal laminar venous phase of the fluorescein angiogram as an area lacking a choriocapillary blush in which normally fluorescent medium and large choroidal vessels were visible against a hypofluorescent background of bare sclera or melanotic outer choroid. These areas of postoperative choriocapillary atrophy were usually well visualised on the preinjection (red-free) fundus photographs as sharply demarcated areas that lacked visible retinal pigment epithelium and in which medium and large choroidal vessels were identifiable against the white background of bared sclera or the mottled, darkened background of melanotic outer choroid. The margins of the area of postoperative choriocapillary atrophy were outlined on optimally enlarged photographs 
Table 2 Scanning laser ophthalmoscope microperimetry and fluorescein angiographic findings in the submacular surgery patients

\begin{tabular}{|c|c|c|c|c|c|c|c|}
\hline $\begin{array}{l}\text { Patient no, } \\
\text { age (years) } \\
\text { sex, eye }\end{array}$ & $\begin{array}{l}\text { Abs } 92 \% \\
\left(\mathrm{~mm}^{2}\right)\end{array}$ & $\begin{array}{l}\operatorname{Rel} 72 \% \\
\left(\mathrm{~mm}^{2}\right)\end{array}$ & $\begin{array}{l}\text { Retinotomy } \\
72 \% \\
\left(\mathrm{~mm}^{2}\right)\end{array}$ & $\begin{array}{l}\text { Fixation distance } \\
\text { in } \mathrm{mm}^{2} \\
\text { (location) }\end{array}$ & $\begin{array}{l}\text { Fixation } \\
\text { grade }\end{array}$ & $\begin{array}{l}\text { Preoperative choroidal } \\
\text { neovascular membranes } \\
\text { size }^{\star}\left(\mathrm{mm}^{2}\right)\end{array}$ & $\begin{array}{l}\text { Postoperative area } \\
\text { of choriocapillary } \\
\text { atrophy }\left(\mathrm{mm}^{2}\right)\end{array}$ \\
\hline $\begin{array}{l}\text { 1, 74, F, RE } \\
\text { Preop } \\
3 \text { Months } \\
6 \text { Months } \\
12 \text { Months } \\
\text { 2, 84, F, RE }\end{array}$ & $\begin{array}{l}3 \cdot 9 \\
7 \cdot 6 \\
7 \\
7 \cdot 3\end{array}$ & $\begin{array}{l}9 \cdot 4 \\
9 \cdot 4 \\
9 \cdot 5\end{array}$ & $\begin{array}{l}1 \cdot 1 \\
1 \cdot 2 \\
1 \cdot 1\end{array}$ & $\begin{array}{l}0.5(\mathrm{PF}) \\
1.9(\mathrm{SN}) \\
1.9(\mathrm{SN}) \\
2.0(\mathrm{SN})\end{array}$ & $\begin{array}{l}2 \\
2 \\
2 \\
2\end{array}$ & $4 \cdot 3$ & $\begin{array}{l}7 \cdot 2 \\
\text { Not tested } \\
7 \cdot 4\end{array}$ \\
\hline $\begin{array}{l}\text { Preop } \\
1 \text { Month } \\
6 \text { Months } \\
14 \text { Months } \\
\text { 3, } 70, \mathrm{M}, \mathrm{LE}\end{array}$ & $\begin{array}{l}\text { Not tested } \\
12 \cdot 6 \\
13 \cdot 5 \\
13 \cdot 6\end{array}$ & $\begin{array}{l}17 \cdot 9 \\
17 \cdot 2\end{array}$ & $\begin{array}{l}\text { Not tested } \\
1.6 \\
1.5\end{array}$ & $\begin{array}{l}2 \cdot 2(\text { IT) } \\
2 \cdot 2(\text { IT) } \\
2 \cdot 2 \text { (IT) } \\
2 \cdot 1(\text { IT) }\end{array}$ & $\begin{array}{l}2 \\
2 \\
2 \\
2\end{array}$ & $9 \cdot 7^{\star}$ & $\begin{array}{l}12 \cdot 1 \\
13 \\
13 \cdot 5\end{array}$ \\
\hline $\begin{array}{l}\text { Preop } \\
6 \text { Months }\end{array}$ & $\begin{array}{l}10.9 \\
17.9\end{array}$ & $23 \cdot 4$ & $1 \cdot 7$ & $\begin{array}{l}\text { Unable } \\
3.0 \text { (IT) }\end{array}$ & $\begin{array}{l}1 \\
2\end{array}$ & $11 \cdot 2$ & $17 \cdot 7$ \\
\hline $\begin{array}{l}\text { Preop } \\
1 \text { Month } \\
6 \text { Months } \\
12 \text { Months } \\
\text { 5, } 71, \mathrm{~F}, \mathrm{RE}\end{array}$ & $\begin{array}{r}6 \cdot 6 \\
12 \cdot 4 \\
11 \cdot 5 \\
11 \cdot 5\end{array}$ & $\begin{array}{l}13 \cdot 6 \\
13 \cdot 5 \\
12 \cdot 4\end{array}$ & $\begin{array}{l}1 \cdot 3 \\
1 \cdot 2 \\
0\end{array}$ & $\begin{array}{l}\text { Unable } \\
\text { Unable } \\
2 \cdot 2 \text { (IT) } \\
2 \cdot 1 \text { (IT) }\end{array}$ & $\begin{array}{l}1 \\
1 \\
2 \\
2\end{array}$ & $6 \cdot 1$ & $\begin{array}{l}13 \\
\text { Not tested } \\
12 \cdot 3\end{array}$ \\
\hline $\begin{array}{l}\text { Preop } \\
4 \text { Months } \\
6 \text { Months } \\
12 \text { Months } \\
\text { LE }\end{array}$ & $\begin{array}{l}21 \cdot 6 \\
24 \cdot 2 \\
23 \cdot 1 \\
21 \cdot 9\end{array}$ & $\begin{array}{l}28 \cdot 6 \\
26 \cdot 3 \\
\text { Not tested }\end{array}$ & $\begin{array}{l}1 \cdot 8 \\
1 \cdot 7 \\
1 \cdot 7\end{array}$ & $\begin{array}{l}\text { Unable } \\
3.0 \text { (IT) } \\
3.0 \text { (IT) } \\
2.6 \text { (IT) }\end{array}$ & $\begin{array}{l}1 \\
2 \\
2 \\
2\end{array}$ & $22 \cdot 3$ & $\begin{array}{l}23 \cdot 6 \\
22 \cdot 8 \\
22 \cdot 3\end{array}$ \\
\hline $\begin{array}{l}\text { Preop } \\
1 \text { Month } \\
6 \text { Months }\end{array}$ & $\begin{array}{l}20 \cdot 2 \\
27 \cdot 9 \\
26 \cdot 3\end{array}$ & $\begin{array}{l}23 \cdot 3 \\
31 \cdot 4 \\
30\end{array}$ & $\begin{array}{l}1 \cdot 7 \\
1 \cdot 7\end{array}$ & $\begin{array}{l}3.9 \text { (IT) } \\
4.0 \text { (IT) } \\
3.8 \text { (TT) }\end{array}$ & $\begin{array}{l}2 \\
2 \\
2\end{array}$ & 21 & $\begin{array}{l}27 \cdot 2 \\
25 \cdot 9\end{array}$ \\
\hline
\end{tabular}

Abs $92 \%=$ absolute scotoma $92 \%$ contrast in $\mathrm{mm}^{2}$; Rel $72 \%=$ relative scotoma $72 \%$ contrast in $\mathrm{mm}^{2}$. Retinotomy $72 \%=$ relative scotoma associated with retinotomy site in $\mathrm{mm}^{2}$; Fixation distance= distance of preferred fixation locus from the centre of the foveal avascular zone $(\mathrm{mm}) ; \mathrm{PF}=$ parafoveal; $\mathrm{SN}=$ superonasal; $\mathrm{IT}=$ inferotemporal

$\star$ Includes the previous photocoagulation scar area.

of the fluorescein angiograms obtained at each postoperative visit. Each scored postoperative photograph was then digitised and used to determine the area of postoperative choriocapillary atrophy using the methods described before. The photographs were outlined by the same person (PFL), who was masked as to the microperimetry results. If an angiogram performed at a postoperative visit were of inadequate quality for assessment, then that angiographic area was designated as not tested for that visit.

\section{Results}

The preoperative vision was worse than $20 / 800$ $(6 / 240)$ in four of the six eyes (Table 1). The average postoperative vision at the final visit was 20/300 (6/90). The results of GuytonMinkowski potential acuity meter testing did not appear to be related to the immediate or final postoperative vision (Table 1). Four of the six study eyes had visual improvement by the 6 month postoperative visit; the other two eyes had stabilisation of vision at the

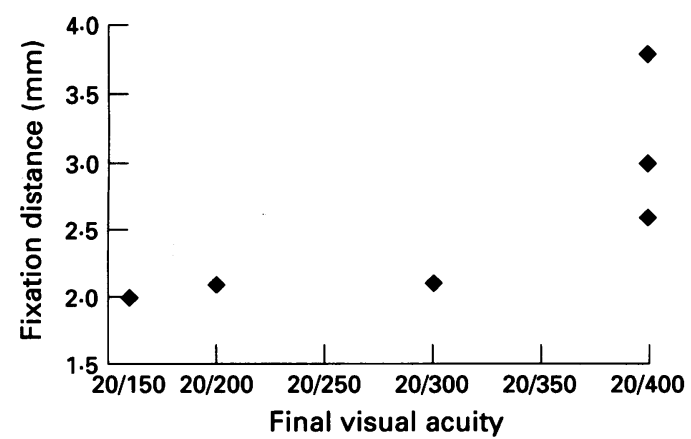

Figure 1 Final postoperative vision was plotted on the $x$ axis. Final preferred fixation distance from the centre of the foveal avascular zone was plotted on the $y$ axis. preoperative level. No eye had a decreased vision postoperatively.

The preoperative and postoperative scanning laser ophthalmoscope microperimetry findings are summarised in Table 2 . The average preoperative absolute scotoma was $15.2 \mathrm{~mm}^{2}$ (range 3.9 to $21.6 \mathrm{~mm}^{2}$ ). Subfoveal choroidal neovascular membrane excision was associated with a $5.5 \mathrm{~mm}^{2}$ (range 3.7 to $7.7 \mathrm{~mm}^{2}$ ) average increase in the size of the absolute scotoma on the first postoperative visit. The size of the absolute scotoma appeared to peak no later than the 6 month postoperative visit. All of the retinotomy sites were associated with a mean relative scotoma of $1.5 \mathrm{~mm}^{2}$ (range 1.2 to $1.7 \mathrm{~mm}^{2}$ ) at the $72 \%$ contrast level at the 6 month postoperative visit. The retinotomy related relative scotoma remained unchanged during the follow up period of five of six eyes, and resolved in one eye (case 4 ) at the 1 year postoperative visit.

Fixation testing revealed that none of the patients fixated within the bed of the excised choroidal neovascular membrane at any time postoperatively. Fixation was localised to a site at the inferotemporal edge of the bed of the excised choroidal neovascular membrane in five of the six eyes at the last postoperative visit. Preoperatively, grade 1 fixation was present in three eyes and grade 2 fixation was present in three eyes. ${ }^{13}$ All patients developed a grade 2 fixation within 1 to 6 months postoperatively. None of the patients developed a grade 3 (well defined, stable) fixation after surgery. In our small series, none of the patients whose final postoperative fixation locus was $2.6 \mathrm{~mm}$ or greater from the centre of the foveal avascular zone had better than $20 / 400(6 / 120)$ vision (Fig 1).

Five of the six choroidal neovascular membranes were classified preoperatively, using the Macular Photocoagulation Study guidelines, ${ }^{9}$ 


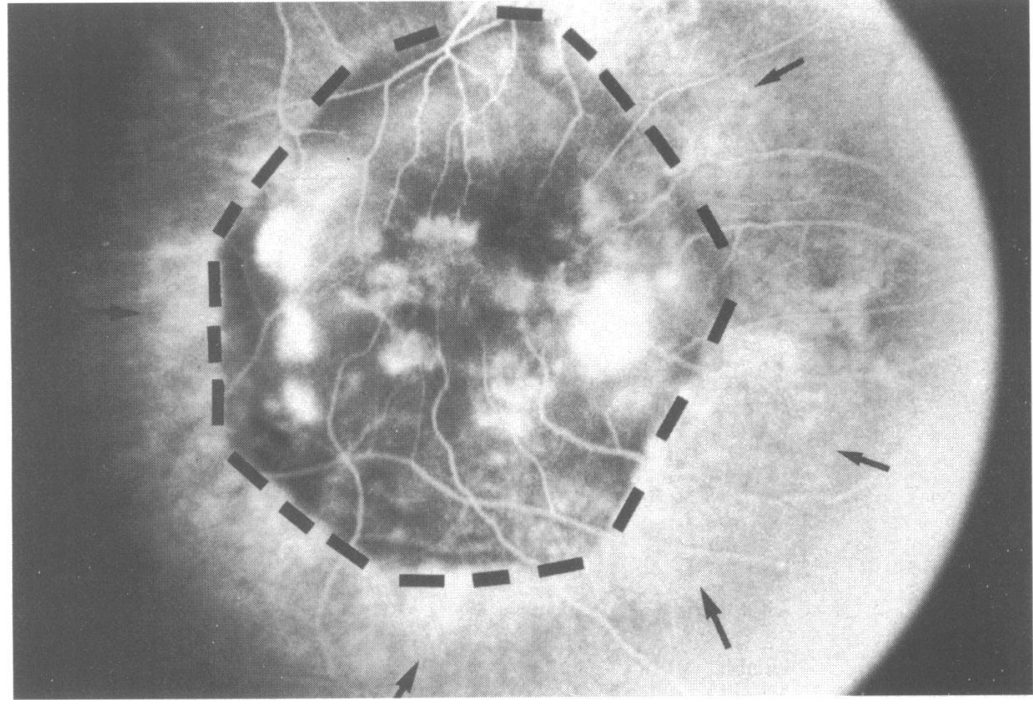

Fig $2 A$

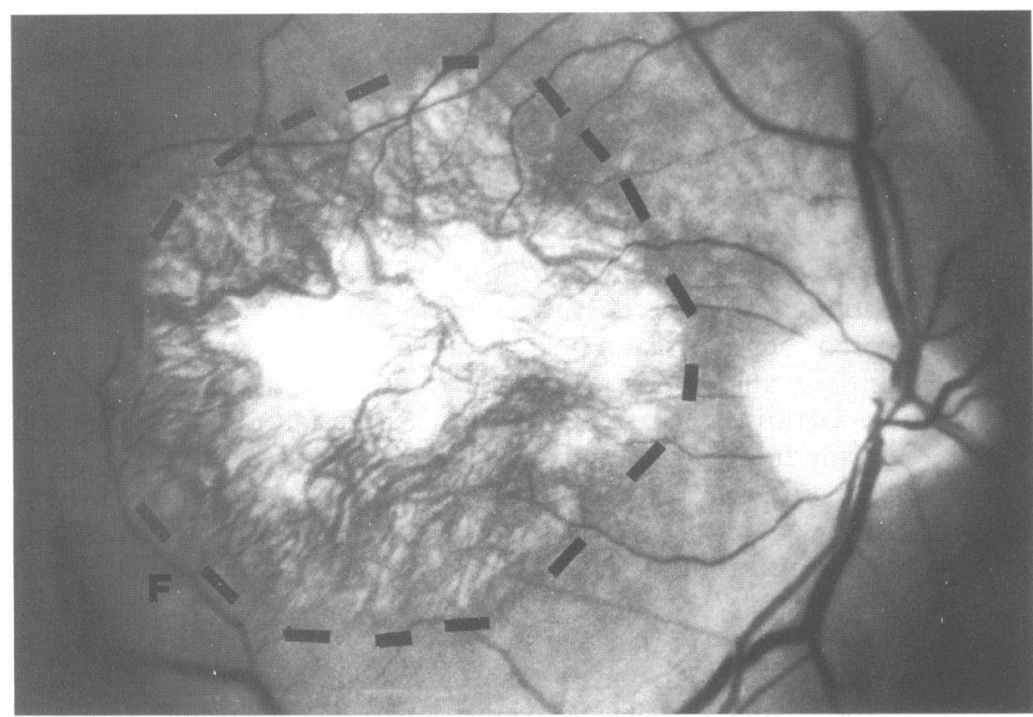

Fig $2 B$

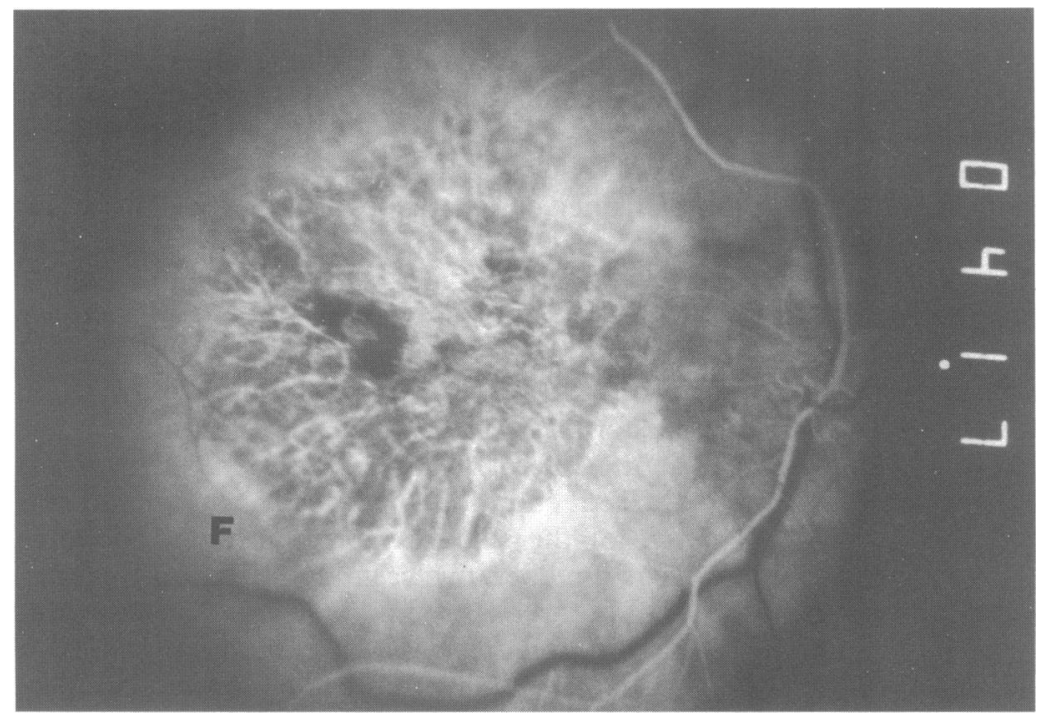

Fig $2 C$

Figure 2 (A) An absolute scotoma is present over the entire area of a well demarcated choroidal neovascular membrane/scar (broken line) in case 3. The surrounding irregular annulus of stereoscopically flat hyperfluorescent staining was associated with a relative scotoma (arrows). This eye had an indeterminate (grade 1) preoperative preferred fixation locus on scanning laser ophthalmoscope microperimetry testing. (B) A monochromatic red-free photograph. (C) An early phase fluorescein angiograph obtained 6 months postoperatively reveal visible large choroidal vessels with overlying choricapillaris and retinal pigment epithelium atrophy in the bed of the surgically excised choroidal neovascular membrane. This region corresponds to the area of absolute postoperative scotoma (broken line). The preferred fixation locus, determined by scanning laser ophthalmoscope microperimetry, is denoted with an ' $F$ '. as well demarcated choroidal neovascular membranes/scars (Fig 2). The sixth lesion was classified preoperatively as an occult choroidal neovascular membrane composed entirely of fibrovascular pigment epithelium detachment. Preoperatively, only one patient (case 2) had recurrent choroidal neovascularisation after previous (juxtafoveal) laser photocoagulation (Fig 3). Subretinal or subpigment epithelial haemorrhage was absent preoperatively from all of the membranes except one (case 5, right eye), which had a thin scant subretinal haemorrhage at its inferior extrafoveal margin that occupied less than $5 \%$ of the entire area of the lesion. An exudative neurosensory retinal detachment greater in size than the angiographically definable choroidal neovascular membrane was present in every case.

The relation of the preoperative fluorescein angiographic features and the preoperative scanning laser ophthalmoscope microperimetry findings was assessed in each patient (Table 2) and revealed that the outlined choroidal neovascular membrane/scar complex (and previous laser scar, if present) corresponded to the size and location of the preoperative absolute scotoma (Fig 2A). Similarly, the outlined postoperative area of choriocapillary atrophy, representing the bed of the surgically excised choroidal neovascular membrane/scar complex (and previous laser scar, if present), corresponded in size and location to the postoperative absolute scotoma (Figs 2B and 3B). No evidence of choriocapillary atrophy was detected in the area of the retinotomy related scotoma in any eye.

\section{Discussion}

The precise pattern of visual loss associated with subfoveal choroidal neovascular membranes in age-related macular degeneration has been incompletely described in the past. Amsler grid testing is an unreliable predictor of retinal scotomatous defects. ${ }^{14}$ Automated perimetry of the central visual field ${ }^{15}$ does not permit exact determination of the presence or location of small relative scotomas, since the visual angular resolution of this technique is only $1 \cdot 6^{\circ}$. In one study, ${ }^{16}$ funduscopically controlled scotometry using the aiming beam of an argon laser as a test object revealed that the test object is visible over 'recent subretinal neovascularisation and is not visible over late subretinal fibrovascular mounds'. This method is limited, however, by the non-standardised power output (target brightness) of the laser used for scotometry. The scanning laser ophthalmoscope has been used successfully to correlate precisely the locations of retinal scotomata with structural retinal lesions, since the tested retinal abnormalities are directly visible to the perimetrist. ${ }^{17} \mathrm{We}$ used quantitative scanning laser ophthalmoscope contrast microperimetry to determine the size and density of the visual loss associated with choroidal neovascularisation in eyes with agerelated macular degeneration, as well as to elucidate the effects of submacular surgery on the visual substrate in these patients. Similar 


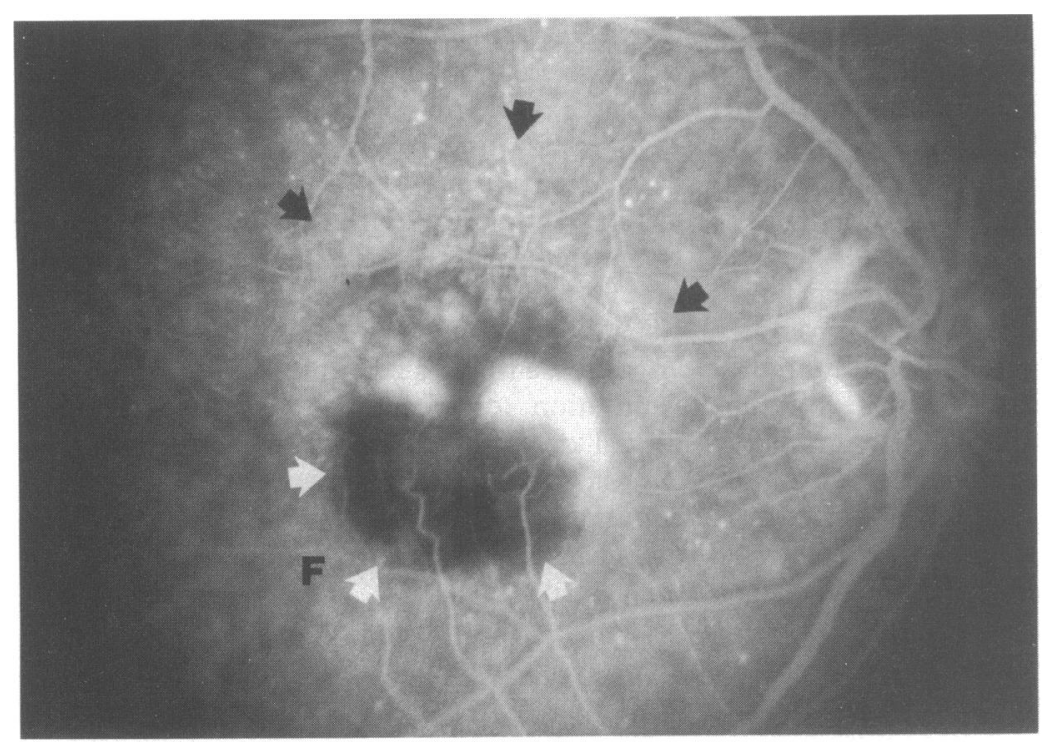

Fig $3 A$

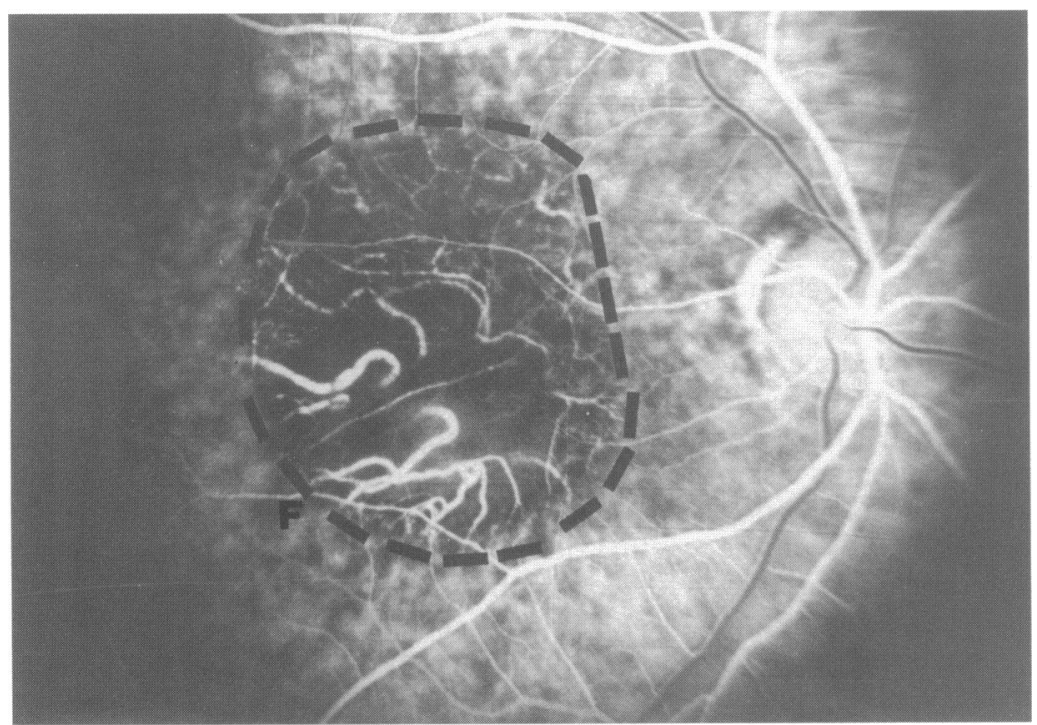

Fig $3 B$

Figure 3 (A) The preoperative late retinal venous phase fluorescein angiograph of case 2 shows areas of fibrovascular pigment epithelial detachment, elevated blocked fluorescence and classic well defined recurrent choroidal neovascularisation (arrows) contiguous with the superior border of an area of persistent choroidal hypofluorescence that corresponds to a laser photocoagulation scar (arrowheads). The preferred fixation locus, determined by scanning laser ophthalmoscope microperimetry, is denoted with an ' $F$ '. (B) The postoperative retinal laminar venous phase fluorescein angiograph reveals large choroidal vessels with overlying choriocapillaris atrophy and retinal pigment epithelium transmission defect in the bed of the surgically excised choroidal neovascular membrane. This area corresponds in both size and location to the area of the postoperative absolute scotoma (broken line). The preferred fixation locus, determined by scanning laser ophthalmoscope microperimetry, is denoted with an ' $F$ '. eyes with age-related macular degeneration and choroidal neovascularisation, the overlying photoreceptors may be either absent or irreversibly functionally damaged before any surgery. Alternatively, iatrogenic damage to the retinal pigment epithelium and/or the choriocapillaris in the bed of the surgically excised choroidal neovascular membranes may have prevented functional recovery in reversibly damaged photoreceptors. In any case, our findings show that excision of subfoveal choroidal neovascular membranes in patients with age-related macular degeneration does not result in functional recovery in retinal areas with preoperative absolute scotomas, even in patients who experience visual recovery following submacular surgery. Our findings also indicate that even though the retinotomy sites created in exudatively detached retina were outside the area of postoperative choriocapillary atrophy, these retinal areas may not function normally. The latter finding may be a consequence of photoreceptor damage secondary to exudative retinal detachment and/or surgical trauma. Preoperative scanning laser ophthalmoscope microperimetry may thus be useful to not only prognostically evaluate age-related macular degeneration patients for subfoveal choroidal neovascular membrane excision, but also to identify an optimal retinotomy site that would minimise iatrogenic visual damage.

The absolute scotoma on the first postoperative visit was greater in size than the absolute scotoma on the preoperative visit in all eyes by an average of $36 \%$ (range 12 to $95 \%$ ), despite improvement or stabilisation of vision in all of our study patients. The increased size of the absolute scotoma in every patient after submacular surgery may reflect iatrogenic damage to functioning photoreceptors, retinal pigment epithelium, and/or choriocapillaris at the margins of the choroidal neovascular complex. In some eyes, part of the increased size appeared to reflect surgical excision of functional photoreceptors and/or retinal pigment epithelium that were adherent to the fibrin rim $^{21}$ that surrounded the neovascular complex (Fig 2A).

Loss of the overlying retinal pigment epithelium does occur with surgical excision of choroidal neovascular membranes in either age-related macular degeneration 2223 or the ocular histoplasmosis syndrome. ${ }^{24}$ Failure to restore a functional retinal pigment epithelium in the bed of the surgically excised choroidal neovascular membranes may compromise vital retinal pigment epithelium mediated trophic factors that support the overlying photoreceptors ${ }^{2526}$ and the underlying choriocapillaris, thereby resulting in photoreceptor (visual) loss and choriocapillaris atrophy. ${ }^{27-31}$ The outer retinal ischaemia induced by choriocapillary atrophy may further compromise photoreceptor viability and function. Impaired wound healing of the retinal pigment epithelium in the bed of the surgically excised choroidal neovascular membrane may therefore explain, in part, the poor prognosis for central visual recovery in eyes with age-related served photoreceptors in the overlying retir In that study, disciform scars equal in size to those excised in our study were associated with a 75 to $100 \%$ loss of photoreceptors. ${ }^{20}$ These histopathological findings, together with our clinical microperimetry data, suggest that in 
macular degeneration compared with eyes with the ocular histoplasmosis syndrome, ${ }^{5-7}$ since retinal pigment epithelium migration on aged Bruch's membrane may be limited. ${ }^{32}$

The size of the postoperative absolute and relative scotomas either remained unchanged or decreased slightly in size in all of our patients after the first postoperative visit. The small decrease in the postoperative absolute scotoma during this period is within the margin of error of our measurement technique (mean $6.5 \%$, range 2 to $10.3 \%$ ). The timing of contraction of the postoperative absolute scotoma (between the 6 and 12 month postoperative visit) is consistent, however, with slow regeneration of reversibly damaged cone photoreceptors following resolution of the exudative neurosensory retinal detachment at the margin of the choroidal neovascular membrane, a process that may require a year or more for completion. ${ }^{33}$ The photopic background illumination employed in our scanning laser ophthalmoscope testing supports the importance of cone photoreceptor changes in explaining our microperimetry findings. In any case, the relatively stable size of the postoperative absolute scotoma during the study period correlates well with the similarly stable size of the postoperative angiographic area of choriocapillaris atrophy.

In our study of eyes with age-related macular degeneration, subfoveal choroidal neovascular membrane excision resulted in visual improvement in all four eyes with preoperative vision less than $20 / 800(6 / 240)$, and visual stabilisation in the other two eyes despite an increase in the size of the scotoma following surgery. This may be related to a change in the preferred eccentric fixation locus. In the four patients whose initial vision was less than $20 / 800(6 / 240)$, grade 1 fixation behaviour was present preoperatively; postoperatively, each of these eyes developed grade 2 fixation behaviour with a preferred fixation locus in the inferotemporal quadrant $(2 \cdot 1$ to $3.8 \mathrm{~mm}$ from the centre of the foveal avascular zone), and visual improvement to $20 / 300$ $(6 / 90)$ to $20 / 400(6 / 120)$ level. Our data differ from those of Weiter et al, ${ }^{34}$ who reported that vision in the $20 / 200(6 / 60)$ to $20 / 400(6 / 120)$ range was found only at retinal distance from the fovea of 0.75 to 1.0 disc diameters $(1.2$ to $1.5 \mathrm{~mm}$ on our scale). Our series is not directly comparable, however, since Weiter et al ${ }^{34}$ included macular lesions other than age-related macular degeneration in their study. Our findings may be reassuring to the surgeon who is contemplating submacular surgery in patients with age-related macular degeneration and large subfoveal choroidal neovascular membranes associated with a large scotomas, but with an area of functionally preserved retina within $4 \mathrm{~mm}$ of the centre of the foveal avascular zone, as defined preoperatively by scanning laser ophthalmoscope microperimetry; in these patients, a postoperative visual acuity of $20 / 400$ $(6 / 120)$ or better may be attainable. In addition, our findings may explain in part the more favourable visual results after submacular surgery in the ocular histoplasmosis syndrome compared with age-related macular degeneration, since the generally smaller membrane size in the former condition may allow a postoperative preferred eccentric fixation locus that is much closer to the centre of a foveal avascular zone.

Elimination of visual confusion at the eccentric fixation locus nearest to the centre of the foveal avascular zone may explain how visual recovery occurred in our patients despite an increase in the size of the absolute scotoma. Resolution of the exudative neurosensory retinal detachment associated with subfoveal choroidal neovascular membranes may have eliminated the source of metamorphopsia in our patients, allowing them to better adapt their visual tasks to a more visually stable eccentric locus. The preference for an inferotemporal retinal locus in our patients is intriguing. This is different from the left or inferior visual field preference reported by Guez et al, ${ }^{35}$ or the random preferred retinal locus reported by Timberlake et $a .^{36}$ However, a superior retinal (inferior field) locus in our patients was unlikely since it would be located in the area of the retinotomy related scotoma. Also, since little functioning retina was present nasal to the area of postoperative absolute scotoma in most of our patients, the inferotemporal fixation locus corresponded with the most functional retinal area nearest to the centre of the foveal avascular zone. Perhaps the surgeon should consider performing the retinotomy slightly inferior to the horizontal meridian that passes through the centre of the foveal avascular zone in an attempt to better preserve the superior retina (inferior visual field), which is important for locomotion and near visual tasks such as reading. ${ }^{36}$ Further studies of scanning laser ophthalmoscope microperimetry in eyes undergoing submacular surgery for subfoveal neovascularisation are warranted.

This study was supported in part by an unrestricted grant from Research to Prevent Blindness Inc, New York and by core grant EYO3040 from the National Institute of Health.

1 National Society for the Prevention of Blindness. Estimated statistics on blindness and visual problems. New York: National Society for the Prevention of Blindness, 1966: Nation.

2 Leibowitz HM, Krueger DE, Milton RC, Kini MM, Kahn HA, Nickerson RJ, et al. The Framingham Eye Study monography. An ophthalmological and epidemiological study of cataract, glaucoma, diabetic retinopathy, macular degeneration, and visual acuity in a general population of 2631 adults, 1973-1975. Surv Ophthalmol (Suppl) 1980 24: 335-609.

3 Kahn HA, Moorhead HB. Statistics on blindness in the model reporting areas, 1969-70. Washington DC: US Department of Health, Education and Welfare, 1973. Publication NIH 73-427.

4 Ferris FL III, Fine SL, Hyman L. Age-related macular degeneration and blindness due to neovascular macudegeneration and blindness due to neovascula
lopathy. Arch Ophthalmol 1984; 102: 1640-2.

5 Lambert HM, Capone A Jr, Aaberg TM, Sternberg P Jr, Mandell BA, Lopez PF. Surgical excision of subfoveal neovascular membranes in age-related macular degeneration. Am $\mathcal{f}$ Ophthalmol 1992; 113: 257-62.

6 Thomas MA, Grand MG, Williams DF, Lee CM, Pesin SR, Lowe MA. Surgical management of subfoveal choroida neovascularization. Ophthalmology 1992; 99: 952-68.

7 Berger AS, Kaplan HJ. Clinical experience with the surgical removal of subfoveal neovascular membranes: short-term postoperative results. Ophthalmology 1992; 99: 969-76.

8 Early Treatment Diabetic Retinopathy Study Research Group. Early Treatment Diabetic Retinopathy Study design and baseline patient characteristics. ETDRS report number 7. Ophthalmology (Suppl) 1991; 98: 741-56

9 Macular Photocoagulation Study Group. Subfoveal neovascular lesions in age-related macular degeneration. Guidelines for evaluation and treatment in the Macular Photocoagulation Study. Arch Ophthalmol 1991; 109:
1242-57. 
10 Dacey MP, Frambach DA. Targets generated with a scanning laser ophthalmoscope have nonlinear contrast. (ARVO abstracts.) Invest Ophthalmol Vis Sci. (ARV abstracts.) Invest 0 phraln

11 Klein R, Davis MD, Magli YL, Segal P, Klein BEK, Hubbard L. The Wisconsin age-related maculopathy grading system. Ophthalmology 1991; 98: 1128-34.

12 Jonas JB, Gusek GC, Naumann GOH. Optic disc, cup and neuroretinal rim size, configuration and correlations in normal eyes. Invest Ophthalmol Vis Sci 1988; 29: 1151-8.

13 Acosta F, Lashkari K, Reynaud X, Jalkh AE, van de Velde F, Chedid N. Characterization of functional changes in macular holes and cysts. Ophthalmology 1991; 98: 1820-3.

14 Schuchard RA. Validity and interpretation of Amsler grid reports. Arch Ophthalmol 1993; 111: 776-80.

15 Janknecht P, Soriano JM, Funk J, Hansen LL. Automatrische Perimetric des zentralen Jesichtsfeldes bei Erkrankungen der Makula. Klin Monatsbl Augenheilkd 1991; 119: 259-63.

16 Kelley JS. Funduscopically controlled scotometry. Trans Am Ophthalmol Soc 1993; 81: 592-629.

17 Timberlake GT, Mainster MA, Webb RH, Hughes GW, Trempe CL. Retinal localization of scotomata by scanning laser ophthalmoscopy. Invest Opthalmol Vis Sci 1992; 22: 91-7.

18 Sjaarda RN, Frank DA, Glaser BM, Thompson JT, Murphy RP. Assessment of vision in idiopathic macular holes with macular microperimetry using the scanning laser ophthalmoscope. Ophthalmology 1993; 100: 1513-8.

19 Sjaarda RN, Frank DA, Glaser BM, Thompson JT, Murphy RP. Resolution of an absolute scotoma and improvement of relative scotomata after successful macular hole surgery. Am f Ophthalmol 1993; 116: 129-39.

20 Green WR, Enger CE. Age-related macular degeneration histopathologic studies. Ophthalmology 1993; 100: histopathologic studies. Ophthalmology 1993; 100

21 Lopez PF, Lambert HM, Grossniklaus HE, Sternberg P Jr. Well-defined subfoveal choroidal neovascular membranes in age-related macular degeneration. Ophthalmology 1993; 100: 415-22.

22 Lopez PF, Grossniklaus HE, Lambert HM, Aaberg TM, Capone A Jr, Sternberg P Jr, et al. Pathologic features of surgically excised subretinal neovascular membranes in age-related macular degeneration. Am f Ophthalmol 1991; 112: $647-56$

23 Grossniklaus HE, Martinez JA, Brown VB, Lambert HM, Sternberg $\mathrm{P} \mathrm{Jr}$, Capone A Jr, et al. Immunohistochemical and histochemical properties of surgically excised subretinal neovascular membranes in age-related macular retinal neovascular membranes in age-related ma

24 Saxe SJ, Grossniklaus HE, Lopez PF, Lambert HM Sternberg P Jr, L'Hernault N. Ultrastructural features of surgically excised subretinal neovascular membranes in the ocular histoplasmosis syndrome. Arch Ophthalmol 1993; 111: 88-95.

25 Faktorovich EG, Steinberg RH, Yasumura D, Matthes MT LeVail MM. Photoreceptor degeneration in inherited retinal dystrophy delayed by basic fibroblast growth factor. Nature 1990; 347: 83-6.

26 LaVail MM, Unoki K, Yasumura D, Matthes MT, Yancopoulos GD, Steinberg RH. Multiple growth factors, cytokines, and neurotrophins rescue photoreceptors from the damaging effects of constant light. Proc Natl Acad Sci, USA 1992; 89: 11249-53.

27 Henkind $P$, Gartner S. The relationship between retinal pigment epithelium and the choriocapillaris. Trans Ophthalmol Soc UK 1983; 103: 444-7.

28 Pollack JS, Kaplan HJ, Del Priore LV, Smith ME. Choriocapillaris atrophy associated with exudative agerelated macular degeneration. (ARVO abstracts.) Invest Ophthalmol Vis Sci (Suppl). Philadelphia: JB Lippincott, 1993: 834.

29 Del Priore LV, Kaplan HJ, Silverman MS, Hornbeck R, Jones J, Swinn, M. Surgical debridement of the retinal pigment epithelium (RPE) in the domestic pig. (ARVO abstracts.) Invest Ophthalmol Vis Sci (Suppl). Philadelphia: JB Lippincott, 1994: 1334

30 Zhang XG, Sugino IK, Zarbin MA. A clinicopathologic correlation of localized mechanical and hydraulic retinal pigment epithelium (RPE) debridement in cats. (ARVO abstracts.) Invest Ophthalmol Vis Sci (Suppl). Philadelphia JB Lippincott, 1994: 1335.

31 Nasir M, Sugino I, Zarbin MA. Clinicopathologic correlation of excised primary and recurrent choroidal neovascularization (rCNV) in age-related macular degeneration. (ARVO abstracts.) Invest Ophthalmol Vis Sci (Suppl). Philadelphia: JB Lippincott, 1994: 1504.

32 Del Priore LV, Liu Y, Hornbeck R, Silverman MS Differential ability of aged versus young human Bruch's
membrane to support repopulation by healthy RPE. (ARVO abastracts.) Invest Ophthalmol Vis Sci (Suppl) Philadelphia: JB Lippincott, 1993: 834.

33 Foulds WA. Factors influencing visual recovery in retinal detachment surgery. Trans Ophthalmol Soc UK 1980; 100 72-7.

34 Weiter J, Wing GL, Trempe CL, Mainster MA. Visual acuity related to retinal distance from the fovea in macular disease. Ann Ophthalmol 1984; 16: 174-6.

35 Guez JE, Le Gargasson JF, Rigaudiere F, O'Regan JK. Is there a systematic location for the pseudo-fovea in there a systematic location for the pseudo-fovea in patients

36 Timberlake GT, Mainster MA, Peli E, Augliere RA, Essock EA, Arend LE. Reading with a macular scotoma. I. Retinal location of scotoma and fixation area. Inves Ophthalmol Vis Sci 1986; 27: 1137-47. 